\title{
LA EVOLUCIÓN DE UN GÉNERO: ELEMENTOS ESTRUCTURALES DE LOS EPIGRAMAS DEDICADOS A ANIMALES DE ÁNITE DE TEGEA *
}

This paper tries to analyze the evolution of funerary epigramm, considering the specific ways of apparition of two of its structural elements (the deceased, and the offerer) in the epigramms devoted to animals by Anyte from Tegea. Along the discussion some specific issues concernig these epigramms are to be dealt with, particularly the problem about their inscriptionality. The analysis phocuses on the degree of variation in Anyte's funerary epigramms with regard to the traditional epitaph (both inscriptional and literary), and the degree of variation in Anyte's (and her contemporaries') epigramms devoted to animals with regard to funerary epigramms devoted to human beings.

\section{INTRODUCCIÓN}

\section{I1. Objeto y método}

1. El objetivo del presente trabajo reside en analizar la evolución del subgénero del epigrama funerario, examinando en detalle la aparición de difunto y encargante como elementos integrantes de este subgénero ${ }^{1}$. El análisis se efectuará en el corpus formado por los epigramas dedicados a animales de Ánite de Tegea ${ }^{2}$, autora a la que se atribuye la innovación consistente en

* Agradezco al Departamento de Filología Clásica de la Universidad de California-Berkeley y especialmente a su director, Dr. D. J. Mastronarde, su amabilidad al poner a mi disposición los medios que me han permitido elaborar este estudio, durante una estancia que tuvo lugar en octubre de 1995.

1 Una relación de los elementos que aparecen en los epitafios se halla en Guarducci (1974, pp. 147-50 - epitafios en prosa - y 157 y ss. para los epigramatísticos), Del Barrio (1989 y 1992) y, básicamente, en la distribución guiada por el criterio formal de Peek (1988).

2 Por razones de espacio, dejo a un lado los dos elementos restantes (el monumento funerario y las circunstancias de la muerte), que trataré en trabajo aparte. Igualmente, queda para un trabajo propio el análisis de la organización (estructura temporal y dramática) de 
componer epitafios literarios dedicados a animales ${ }^{3}$. El citado análisis incidirá en algunos problemas relacionados con estos epigramas, especialmente en la discusión relativa a su inscripcionalidad, y permitirá puntualizar la posición cronológica de Ánite en el marco de la escuela peloponesia.

2. El análisis se centra en anotar: 1) el grado de variación que los epigramas funerarios de Ánite ofrecen respecto del epitafio tradicional - inscripcional y literario -; 2) el grado de variación que los epigramas funerarios de esta autora (y sus contemporáneos) dedicados a animales ofrecen en relación a los epigramas funerarios dedicados a humanos.

Por ello, el análisis se estructura de forma sistemática en tres subapartados: panorama de la tradición previa, panorama del epitafio en Ánite dedicado a humanos y panorama del epitafio en Ánite dedicado a animales.

3. A lo largo de este análisis, trataré de conjugar los datos inscripcionales y literarios, engarzándolos cronológicamente en referencia a Ánite:

a) Para los paralelos inscripcionales he considerado el trabajo de G. Kaibel y, especialmente, la compilación de W. Peek, de gran utilidad por su ordenación temática (asociada a una manifestación formular).

b) En lo que respecta a las fuentes literarias la fuente principal es la $\mathrm{An}$ tología ${ }^{4}$ :

I) para calibrar las aportaciones de Ánite considero como precedentes literarios los autores presimonídeos y - con reservas por la heterogeneidad de su cronología - la colección simonídea;

los epigramas. Prescindo de los elementos propios de épocas posteriores a la primera generación de poetas helenísticos (v. gr. los datos biográficos del difunto, la consolatio, etc.), porque no aportan ninguna información relevante para el tema que nos ocupa.

${ }^{3}$ La atribución de esta innovación a Ánite se halla, sin duda, en conexión con su ubicación en la primera generación de poetas helenísticos (s. III a. C.), y en concreto, como primera figura cronológica de la escuela epigramatística del Peloponeso. La importancia de la primacía cronológica deviene de que en su obra se gestaría la transición del epitafio inscripcional al literario creando un modelo que se refleja en sus imitadores: Nicias, Mnasalces, etc.

${ }^{4}$ La transmisión de las colecciones de epigramas constituye una de las cuestiones más estudiadas en la labor filológica más reciente desde que a principios de siglo ha sido accesible el códice palatino, recopilación de la que el manuscrito planudeo parece ser una breve refección (en adelante $A P$ y $A P l$ respectivamente). Desde la edición de los epigramas antologizados de R. Weisshäupl (Die Grabgedichte der Griechischen Anthologie, Viena, 1989), se suceden las ediciones de los epigramas contenidos en los dos manuscritos citados: de Reitzenstein, de Brunck, de Dübner y Stadmüller. A las incompletas ediciones de Beckby, Waltz y Paton, sigue el estudio desglosado por autores - acompañado de comentario - de Gow-Page, en su Hellenistic Poetry y The Garland of Philip, así como la obra en 
II) como autores coetáneos considero de la sección de la «Corona de Meleagro» — como ha sido definida por Gow-Page (1965) - la porción de autores que se estima contemporánea al floruit de Ánite en el tránsito de s. IV al III a. C.; es decir, la obra creada por autores localizados entre 310-290 (cf. sección A de Page, 1975: x-xi): Antágoras, Mero, Nossis, Perses, Simias, etc.;

III) considero la posible influencia de Ánite sobre autores posteriores, ubicados a principios del s. III a. C. (ca. 275) como Arato, Asclepiades, Calímaco, Nicias, Posidipo y Teócrito; a mediados del siglo (ca. 250) como Euforión, Hegesipo, Leónidas de Tarento, Mnasalces, etc.; hacia la segunda mitad de la centuria (ca. 250-200) como Dioscórides, Niceneto, Fédimo, Rianno, Teodóridas, etc. o finales del s. III a. C. (ca. 220-180) como Samio. Así mismo, consideraré la obra de autores de datación incierta entre los ss. III y II a. C. como Arquias ${ }^{5}$, Aristodico de Rodas, Diotimo, Pánfilo, Faenno, Timnes, etc. (cf. secciones A-E e I de Page, 1975, pp. X-XI). La obra de estos autores - como la de los citados en $I I)$ - es relevante también por la temática y forma que presentan en sus epigramas funerarios, no sólo dedicados a animales, sino también a humanos, para el desarrollo del género sepulcral que aquí abordo ${ }^{6}$.

IV) Excepcionalmente, se examinan epigramas posteriores por ser relevantes para observar la orientación que adquiere el subgénero de animales en su desarrollo, pertenecientes a la Corona meleágrica como los compuestos por Antípater de Sidón (s. II a. C.) y por el propio Meleagro (s. I a. C.), procedentes de la Corona de Filipo (s. I) como los compuestos por Antípater de Tesalónica y Marco Argentario, e incluso pertenecientes al Ciclo de Agacías (s. VI) como los compuestos por Damocaris y Agacías.

\section{Relación de epigramas}

4. De Ánite de Tegea, nos ha llegado una veintena de epigramas transmitidas en el conjunto epigramatístico de las Antología Palatina y Planudea, así como en la obra de Pólux ${ }^{7}$.

solitario de Page, Greek Further Epigrams, a los cuales remito en lo relativo a los autores citados en $\S 3$. El estado actual de la cuestión es accesible en el reciente trabajo de A. Cameron (1993). El texto utilizado en este trabajo responde a la edición de Gow-Page, cuya notación se consigna en corchetes cuadrangulares.

5 Al nombre de «Arquias» ha sido adscrita obra de diversa mano. Los poemas del subgénero de animales adscritos a su autoría que incluyo son los atribuidos por Gow-Page (1968, pp. 432-4) al autor meleágrico denominado «Arquias de Mitilene».

6 Por este motivo, de los citados autores sólo se ha examinado la obra de aquéllos que incluyen epigramas funerarios.

7 Sobre la vida de la poetisa y su obra, además de los citados estudios, es de interés la tesis doctoral de J. M. Baale y el estudio de D. Geoghegan, Roma, 1979. Cinco de estos veinte poemas se consideran espúreos; de entre ellos, el epigrama VII 215 [12] dedicado al delfín, pertenece al subgénero de animales, v. § 5. II (cf. Gow-Page, 1965, p. 91). 
5. Ánite es la autora de la que más poemas se han conservado que instancian el subtipo dedicado a animales, además de ser considerada como la creadora del mismo. De los diez epigramas de Ánite que pertenecen al género sepulcral, cinco están consagrados a animales - el número más elevado frente a cuatro a doncellas (VII 486 [5], 490 [6], 646 [7] y 649 [8]) y uno a un soldado caído en batalla (VII 724 [4]). Cuatro de estos epigramas dedicados a animales nos han sido transmitidos en el libro séptimo del manuscrito palatino, mientras que en la Antología Planudea figuran en la parte B: VII 208 [9], VII 202 [11], VII 215 [12] y VII 190 [20]; el quinto es transmitido por

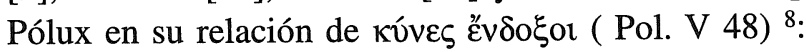

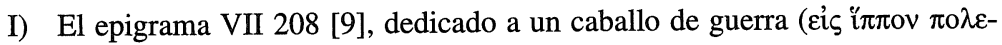

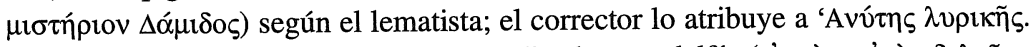

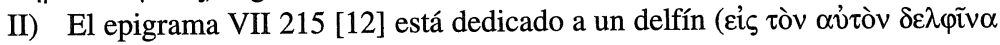

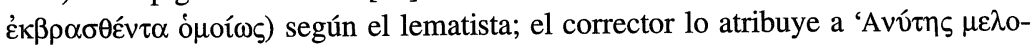
Toเõ̃ este poema está ausente del manuscrito planudeo. Todos los epigramas considerados presentan la estrofa habitual en Ánite: dos pares de dísticos elegíacos, salvo éste, y otro epigrama atribuido a Ánite, cuya autoría es desestimable (el epitafio de las jóvenes de Mileto AP 492 [23]). Por este motivo, se ha sometido a detallado examen la atribución de este poema, pero no se registra ninguna duda sobre su autoría, que es unánimemente asignada a Ánite; además, los datos internos del poema (lenguaje, estilo, contención y gusto por la naturaleza) apoyan la tradición.

III) El epigrama VII 202 [11] está dedicado a un animal alado; el lematista señala una cigarra (

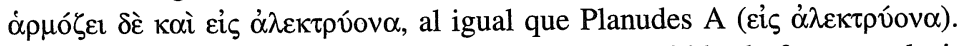

IV) El epigrama dedicado a un perro es transmitido de forma exclusiva por

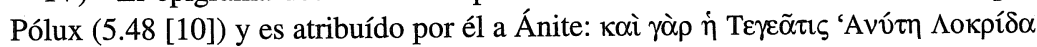

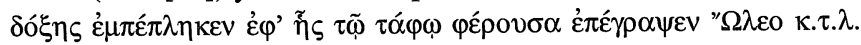

V) El epigrama VII 190 [20] está dedicado a una cigarra y a un saltamontes,

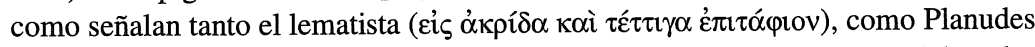

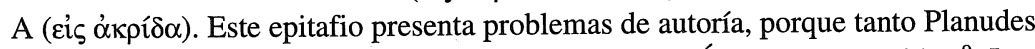
como el corrector consignan una doble atribución: de Ánite o de Leónidas ${ }^{9}$. Los

${ }^{8}$ Los epigramas funerarios dedicados a animales son transmitidos en el conjunto de epigramas funerarios constituidos por el libro VII de la $A P$, y en el capítulo III de $A P l$. En el manuscrito palatino, estos epigramas componen una serie «cerrada» (VII 194-VII 203) como es habitual en esa primera sección del libro VII (epigramas 1-363), sección que no es sino el resultado de una agrupación temática procedente del conjunto meleágrico (frente a la yuxtaposición inordenada de los diversos ciclos antológicos que se observa en la parte final de dicho libro (del epigrama 363 en adelante). Precisamente en esta secuencia compuesta por los epigramas dedicados a animales, que Céfalas debió de incorporar de la Corona meleágrica, se conserva el orden alfabético que debió imponer el propio Meleagro.

9 A pesar de la doble adscripción de este epigrama, la atribución a Ánite es unánimemente aceptada, pues tampoco el intento de Stadtmüller de atribuirlo a Leónidas de Ale- 
editores de Ánite han rechazado de forma casi unánime la autoría de Leónidas de Tarento, principalmente por la diferencia de estilo, ya que el epigrama contrasta con el estilo verboso y artificioso del autor tarentino ${ }^{10}$, por lo que lo incluyo en el corpus de Ánite en examen.

\section{ANÁLISIS}

\section{II1 El difunto}

6. Panorama de la tradición previa. En el epitafio tradicional la mención del difunto era el elemento esencial del epigrama y ello por la propia finalidad del epigrama, ligada al monumento funerario, a saber: perpetuar la memoria del individuo por medio de su invocación (lectura en voz alta). Esta «invocación» del difunto constituía su vínculo con el mundo de los vivos (cf. E. Rohde, 1973; E. Vermeule, 1974; G. Gnoli-J. P. Vernant: 1982). En algunas sociedades muy comunitarias, como la espartana, el monumento sepulcral sólo podía celebrar el recuerdo de personajes que habían prestado un servicio a la comunidad (cf. E. Rohde, 1973, p. 229, n. 63). Una muestra de esta época la constituye el famoso epigrama a los caídos en las Termópilas (Hdt. VII 228 = Peek n. ${ }^{\circ}$ 4) y los polyandria citados por Peek (1988, pp. 1-14]). La gloria del individuo quedaba indisolublemente ligada a la de la colectividad y esta ligazón se palpa en la mención de la patria en los epitafios tradicionales de guerreros ${ }^{11}$; la estructura formal de éstos, caracterizados por

jandría ha resultado convincente. Por otra parte, ha contribuido a oscurecer la cuestión de la autoría la azarosa transmisión de ese epigrama, desgajado en el ms. palatino por la imitación de Marco Argentario (VII 364), perteneciente a la Corona de Filipo e introducida a modo de glosa por el corrector. Por último, es conocida la confusión en la que incurre Plinio en la interpretación del nombre de Mvpó - no el escultor Mirón, sino la joven Mero - confusión que sustenta su noticia errónea de que Erinna compuso un poema de este tenor (cf. Reitzenstein, 1893, p. 143; Baale, 1905, p̉p. 153 y 158-60).

${ }^{10}$ Cf. la opinión de Reitzenstein a partir de la comparación con el epigrama VII 198, y los argumentos léxicos y métricos aducidos por Baale (1905, pp. 156-7) (aunque estos argumentos poseen, a mi parecer, mera fuerza indirecta, y no constituyen pruebas formales). Gow-Page explican la adscripción a Leónidas como una confusión a partir de una referencia al epigrama dedicado también a una cigarra de este autor — el VII 198 —.

11 El epitafio arcaico, por su estilo, selección léxica, métrica hexamétrica y por el mundo heroico que evoca, sobre sepulcros de guerreros, cuya memoria perpetúa la gloria de la patria, se halla ligado íntimamente a la poesía épica (cf. Freindländer - Hoffleit, 1948. p. 7; Adrados, 1988, p. 164); sobre la difícil cuestión relacionada con la composición oral y el origen del género epigramático cf. la exposición de Raubitschek (1968, pp. 3-4), y especialmente la opinión de Pfohl en el debate sobre la exposición de Raubitschek, recogido en el mismo volumen. 
su suma brevedad, incluía la mención del difunto, de su familia y de su patria (cf. Waltz, 1960, p. 26 y Guarducci, 1974, p. 147).

7. Pero pronto el deseo de individualidad hace que los epitafios celebren no sólo la memoria de hombres ilustres que dan gloria a la comunidad, sino también la de individuos particulares, en un derroche que trata de ser paliado por las leyes. Ejemplos de ello los encontramos en epitafios inscripcionales ( $v$.

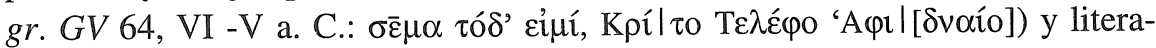

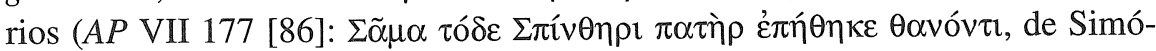
nides). Al tiempo, se registran las primeras muestras de epigramas ficticios, no destinados a ser inscritos, como el epitafio burlesco para la tumba de Timocreón de Rodas atribuido a Simónides (AP VII 348; cf. Page, 1981, pp. 93-95 y Cameron, 1993, p. 2). El giro copernicano que experimenta el epigrama en el tránsito de la época clásica al helenismo responde a la conjunción de dos factores: el tránsito del género de su funcionalidad real a género literario y la apertura temática (cf. Symonds, 1920: 21 y ss.; Körte, 1929: 6 y 27; Brioso, 1988: 781 y ss.). Este último fenómeno se enraiza en el colapso de la elegía, que provoca que sus temas, metro y métodos de composición se trasvasen al epigrama (cf. Couat, 1931, p. 178 y ss) ${ }^{12}$.

8. Panorama en los epitafios de Ánite dedicados a humanos. En la evolución helenística, todas las capas y estratos sociales irrumpen en el género funerario: mujeres, jóvenes doncellas, niños, esclavos, campesinos, mendigos, etc. ${ }^{13}$ son objeto del honor de un epitafio cuya inscripcionalidad en ocasiones está sujeta a debate. Así, en la propia Ánite encontramos epitafios a jóvenes doncellas (como VII 486; cf $\S$ 5) con su reflejo inscripcional ( $G V 1385$ [IV a.

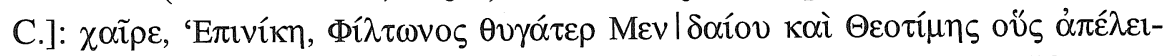

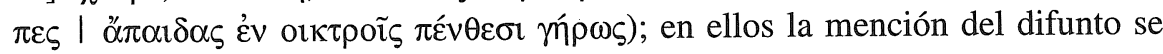
efectúa siempre por la consignación del nombre propio. También en los epitafios a humanos de otros autores meleágricos es obligada la identificación del

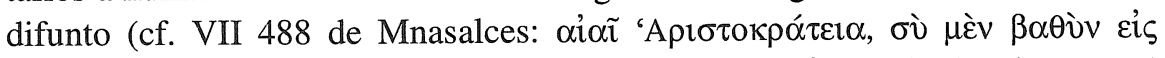

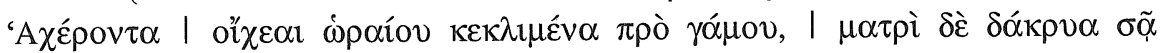

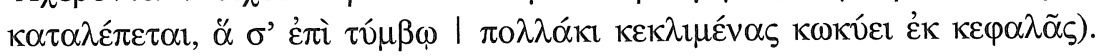

12 Cf. respecto a la indistinción de epigrama, elegía y escolio Gentili, 1967, p. 37 y ss. y Giangrande, 1967, p. 91 y ss.

13 Alude a este cambio de sensibilidad Rohde (1973, p. 236), subrayando que el culto de las almas se convierte en una operación privada y familiar, con lo que se rebajan las manifestaciones sublimes de la vida al nivel de lo idílico, como lo evidencian las representaciones artísticas de las cerámicas del Ática del s. IV. 
9. Panorama en los epitafios de Ánite dedicados a animales. En los epigramas en los que el lugar del difunto es asumido por un animal se revela con nitidez la difusión temática y el deseo de variación helenísticos; la importancia de esta cuestión deriva de que esta serie de epigramas funerarios reciben su carácter tipológico precisamente de este elemento compositivo.

10. En relación a este elemento, la mención del animal fallecido, hay que destacar varios aspectos, como la tipología de animales seleccionados (1.1), la individualidad / genericidad de la mención del animal (1.2), el motivo del «elogio del difunto» en relación a la selección del animal (1.3), la selección del animal en relación a la funcionalidad del epigrama: ficción $v s$. inscripcionalidad (1.4) y la consignación formal del nombre del difunto (1.5).

\section{II1.1 Tipología de los animales}

11. La selección de animales presenta una amplia gama, pues incluye domésticos (caballo: VII 190 [20]; perro: Poll. V 48; ave: VII 202 [11]) y en estado salvaje (delfín VII 215 [12]). Entre ambos extremos se halla el epigrama de los insectos: si bien su cautividad, aunque infrecuente, es posible, la ausencia de toda referencia en el epigrama al género de vida concreto convierte toda interpretación en simple conjetura. Es evidente que la cuestión de la domesticidad-cautividad posee una relación muy estrecha con la inscripcionalidad del epigrama: la posibilidad de que un amo dedique una «tumba» a un animal querido con unos sencillos versos es aceptable, como lo demuestran las inscripciones de este tenor (v. gr. $G V 587$, dedicada a un perro de compañía, mascota de una joven; cf. el texto en $\S 15 \mathrm{IIb}$ ), pero la posibilidad de que se erija un sepulcro con un epigrama a un animal no doméstico parece poco probable.

\section{II1.2. Mención genérica / individuada}

12. Existen dos opciones en la mención del animal, que ésta sea explícita (I) o no (II):

Ia) Los animales carecen de personalidad, de «yo», lo cual se manifiesta en su mención en los epigramas de Ánite por medio de referencias a su especie

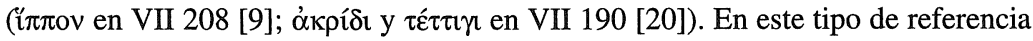
explícita el animal cobra individualidad de forma secundaria por asociación a su dueño (cf. §32.II).

Ib) Pol. V 48 parece mostrar otra posibilidad de mención explícita: el nombre del animal. En este aspecto, el epigrama dedicado a animales se acomoda al canon epitafial; pero la semejanza es superficial, porque el nombre del animal es un

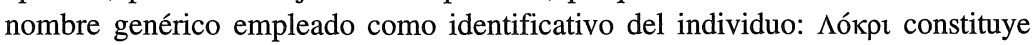


una denominación de origen, basada en la fama de buenos cazadores de que gozaban los perros oriundos de Lócride (de forma similar, alude a esta característica el nombre parlante $\Phi v \lambda$

II) La mención indirecta del animal sintoniza con el gusto de Ánite por sugerir antes que explicitar datos y relaciones (cf. Díaz de Cerio 1996, §77). En el epigrama VII 202 [11] no existe ninguna referencia clara al animal fallecido; la referencia al batir de las alas ( $\pi v \kappa \imath v \alpha i ̄ \varsigma ~ \pi \tau \varepsilon \rho v ́ \gamma \varepsilon \sigma \sigma \mathrm{l} \varepsilon \rho \varepsilon ́ \sigma \sigma \omega v$ ) parece ajustarse a un gallo en la opinión del corrector y Planudes A, frente a la del lematista (cf. $\S \S 5$ y 15.III). En el epigrama VII 215 [12], a diferencia de los restantes epitafios de animales, la autora desaparece por completo y la narración se pone en boca del propio animal en sus momentos postreros, de forma que la referencia a un delfín sólo se deduce por la mención a los mascarones de proa (cf. el texto y su interpretación en nt. 23).

\section{II1.3 El elogio del difunto y la selección del animal en la elección temática}

13. El elogio del difunto constituye un elemento temático del epitafio elemento poco desarrollado en los epigramas arcaicos, pero que en la evolución del género tiende a una mayor elaboración ${ }^{14}$. El elogio del difunto enlaza con el tono epidíctico de los discursos fúnebres y crea una cierta zona de indefinición entre ambos subgéneros cuando el difunto constituye una figura histórica a quien se dedica un epitafio, presumiblemente literario. Sin embargo, fue un elemento desarrollado también en los epigramas inscripcionales, como lo

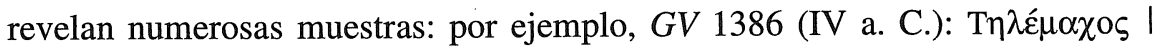

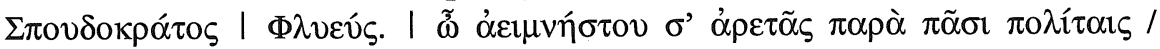

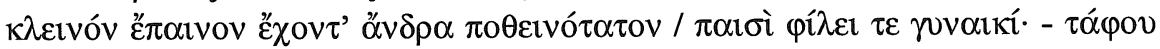

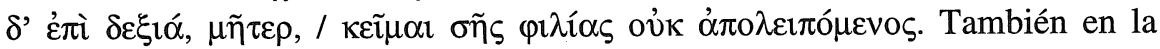
$A P$ hallamos epigramas que incorporan este elogio, especialmente de individuos concretos; en ellos se desarrolla el motivo del status social del difunto y de su lazo familiar con el encargante del monumento. Una muestra de ello se halla en el poema VII 490 [6] - perteneciente a Ánite -, que expone el elogio de la juventud y belleza de la doncella difunta.

14. En los epigramas funerarios dedicados a animales el elogio del animal se enfoca desde la perspectiva de su conexión con el dueño: se ensalza el valor en batalla del caballo de guerra, la velocidad del perro de caza, la canoridad del ave, el murmullo de los insectos, etc. De esta manera, se conserva en estos

14 Este elemento se enraiza en el banquete del ritual del culto a las almas tras el sepelio, pues el miedo al difunto - al que se creía presente - dictaba el carácter elogioso (cf. Ro'dde, 1973, pp. 230-1). 
epigramas el elemento habitual de los epitafios tradicionales, adaptado a la nueva temática.

15. La selección de una determinada especie animal es susceptible de diverso tratamiento en el epitafio, dependiendo del tipo de ámbito humano al que se asocie el animal, y ello se registra por medio de la selección léxica:

I) Los epigramas dedicados a caballos presentan dos modalidades temáticas: la que lo asocia a la gloria guerrera como instrumento en la batalla (Ia) y la que lo asocia a las carreras de velocidad (Ib):

Ia) el epigrama funerario de Ánite en examen celebra la memoria de un caballo de guerra; la autora evoca el ambiente heroico por medio de una cuidada selección de voces homéricas, manifiestamente en el uso adjetival ( $\mu \varepsilon v \varepsilon \delta \alpha i ́ o v$

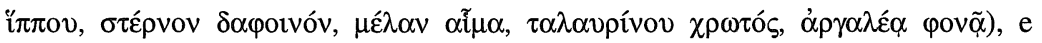

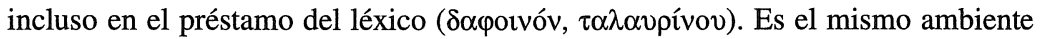
que respiran los epigramas votivos de armas de guerra como el VI 123 [1] de Ánite, los VI 9 [3], 125 [4], 128 [5], 264 [6] de Mnasalces, o el 6. 122 [1] de Nicias y en el citado epitafio del guerrero de VII 724 [4] de la misma autora, y, en suma, de los epitafios tradicionales de guerreros que conforman un género tradicional (cf. paralelos inscripcionales como $G V 1224$ [VI a. C.]: $\sigma \tau \bar{\varepsilon} \theta \imath$ кoì

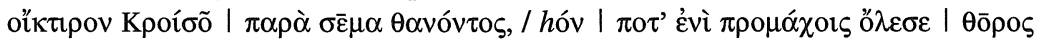
"Ap $\bar{\varepsilon} \varsigma$ ).

Ib) En el epigrama de Mnasalces AP VII 212 [11] el elogio del caballo se

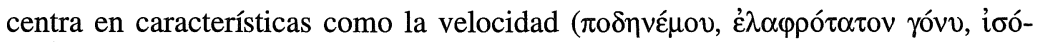
$\delta \rho \mu_{0}$, $\left.\mu \tilde{\alpha} \kappa_{\kappa} \varsigma\right)$. Este aspecto habla de un mundo más cotidiano e, indudablemente, resta lirismo al conjunto. La comparación con un pájaro —en torno a la velocidad - en el último verso supone una innovación de Mnasalces con respecto a su evidente inspiración en el epigrama de Ánite, sobre la que se fundamenta el error del lematista, que ha tomado el apodo del nombre de la ave (Ai $\theta v i ́ a \varsigma)$ por

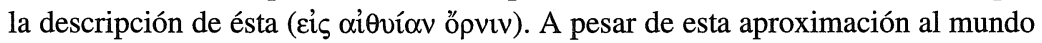
cotidiano, hallamos paralelos inscripcionales, dedicados a un caballo de carreras,

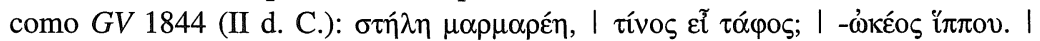

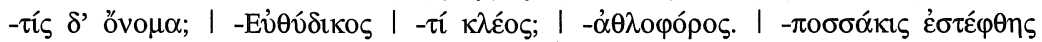

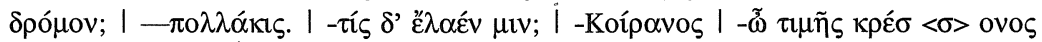
$\dot{\eta} \mu 1 \theta \varepsilon ́ \omega v$ (no obstante, la posterioridad del paralelo inscripcional hace incierto si la obra de Mnasalces constituye una innovación literaria que permite la ampliación del género inscripcional o si reproduce una costumbre de sus días).

II) El perro, como animal doméstico, aparece en epitafios también en dos modalidades temáticas: como instrumento de caza (IIa) y como mascota doméstica (IIb):

IIa) Como animal de caza es descrito el perro del epigrama de Ánite Pol. V 48 [10], que elogia las cualidades del animal relevantes para su oficio, como la

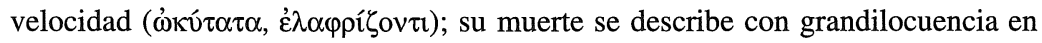
conexión con el servicio a su amo. Un ejemplo inscripcional con esta temática 


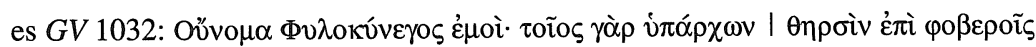

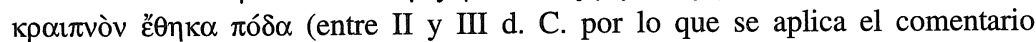
apuntado en ib); en la propia $A P$ se encuentra el VII 211 de Timnes [5], posterior a Ánite (se discute su ubicación entre los ss. III y II a. C.).

IIb) $\mathrm{Al}$ perro como mascota de adultos y niños se dedican varios epigramas

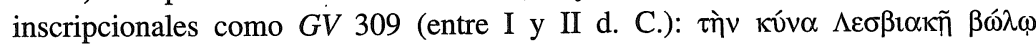

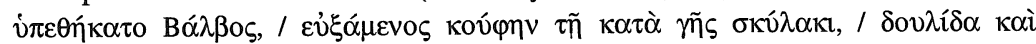

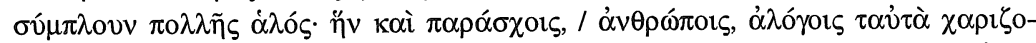

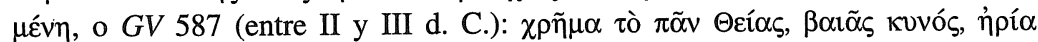

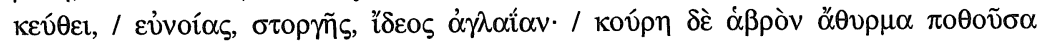

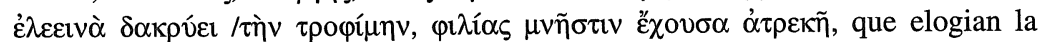
dulzura del animal y fidelidad en esa atmósfera afectiva tardohelenística.

La elección del perro acerca el género del epigrama al mundo cotidiano de los animales domésticos como seres queridos para sus amos, pero desprovistos de esa grandeza asociada tradicionalmente al género epitafial aún perceptible en la gloriosa muerte guerrera del caballo: la desvinculación del mundo heroico, a pesar del esfuerzo que se percibe en Ánite Pol. V 48, es irreversible.

III) Los epitafios dedicados a aves tienen reflejo inscripcional nulo; en la Colección de Céfalas figura un número de ellos que Planudes reunió bajo el

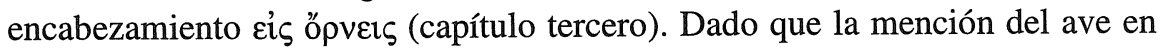
VII 202 de Ánite - como se expuso en $\S 12$ II — es sumamente indirecta, no caben precisiones acerca del tipo de ave al que se refiere.

La misma elección temática aparece en poemas que constituyen versiones dentro del contexto meleágrico (IX 70 [14] de Mnasalces y VII 210 [63] de Antípater de Sidón dedicados a a un ruiseñor; VII 191 [20] de Arquias dedicado a un ave desconocida, como VII 199 [4] de Timnes - también un ruiseñor, en la opinión de Waltz -). Especial problema plantea el poema VII 203 [1] de Simias a una perdiz, ya que puede considerarse como coetáneo del de Ánite o una imitación del mismo, pues no es posible rastrear la dirección de la influencia y la imposibilidad de precisar la datación de este autor aumenta la dificultad 15; cf. n. 16). También están dedicados a la muerte de un ave una perdiz - los poemas tardíos VII 204 y 205 de Agatías y VII 206 de su discípulo Damocaris. El largo lapso de tiempo que cubre el tratamiento de esta misma temática de la muerte del ave permite ilustrar con detalle la evolución que sufre el género epigramático.

15 Se rastrean llamativas coincidencias formales como el inicio ov̉кétı con futuro y la estructuración temporal con retroceso al pasado en ambos epigramas; pero frente al submotivo del ruido producido por las alas del poema de Ánite aparece en el de Simias la

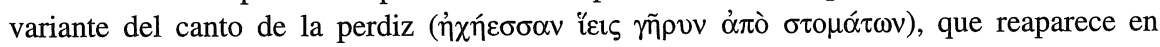

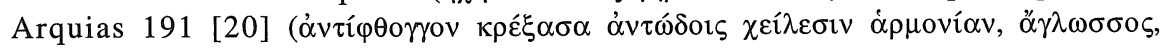

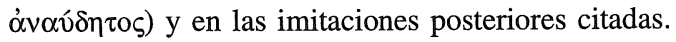


En efecto, en estos poemas meleágricos destaca el motivo nítido el canto del ave, que constituye el apoyo de la relación amo-mascota (VII 210 [63] de Antípater de Sidón, VII 199 [4] de Timnes y VII 191 [20] de Arquias), en claro contraste con el ave descrita por Ánite, que se sirve del batir de alas para

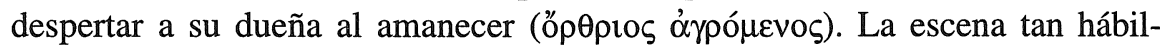
mente trazada por esta poetisa no reaparece en ninguno de los poemas posteriores dedicados a aves. En cambio, el submotivo específico de la muerte causada por un felino es el tema central de las imitaciones muy posteriores de Agacías y de Damocaris. Esta preferencia temática se halla en consonancia con el gusto tardohelenístico por la presentación de escenas truculentas en el género sepulcral que es, además, igualmente perceptible en los epigramas funerarios dedicados a humanos ${ }^{16}$.

Por otra parte, los poemas citados muestran una progresiva artificiosidad en el tratamiento del tema, manifiesta, entre otros aspectos, en el abandono de la evocación del difunto y en la proliferación de alusiones mitológicas: así, el citado poema VII 210 [53] de Antípater dedicado a un ruiseñor cuyas crías son devoradas, con su alusión final al mito de Procne y Filomela, no se distingue del epigrama epidíctico de tema similar IX 70 [14] de Mnasalces. En tales composiciones no existe la estructura formal de epitafio, pues no se registran los elementos canónicos de todo epigrama funerario, más bien constituyen poemas de carácter elegíaco que incluyen el motivo de la muerte de un animal. De igual manera se observa en los epigramas posteriores de Agacías y Damocaris el desplazamiento de la forma epitafial hacia la elegíaca: en VII 205 el núcleo temático se ha desplazado y pivota ya sobre el felino asesino de la perdiz, cuya muerte queda como un mero trasfondo desdibujado; lo mismo sucede en la versión de VII 206 compuesto por Damocaris en respuesta a su maestro en lo que parece constituir una competición literaria de variaciones sobre el mismo tema. El incremento del efectismo retórico y el aumento del elemento mitológico - con frecuencia flojamente hilvanado en el poema son dos rasgos llamativos de estas composiciones indicadoras del decaimiento del género en su evolución tardía ${ }^{17}$.

16 Compárese la escena del felino arrancando la cabeza a la perdiz y el rescate subsiguiente del resto del cuerpo en Agacías frente a la sutil insinuación en Ánite de una acción similar. Un paralelo del gusto por lo paradójico y truculento en los epitafios a humanos lo ofrece VII 276 [17] de Antípater de Tesalónica, una variación del profuso tipo del epitafio del náufrago, que en esta ocasión ha sido medio devorado por los peces y es, por tanto, enterrado con ellos. Esta cuestión requiere un tratamiento de detalle a propósito del elemento epitafial denominado «circunstancias de la muerte», excluido de análisis en el presente trabajo.

17 El retoricismo se advierte tanto en la propia expresión lingüística (v. gr. en VII 204

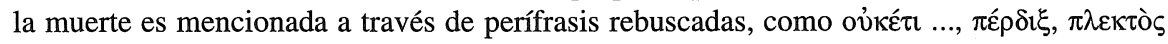


IV) La elección de los insectos, sorprendente para la sensibilidad actual, constituye una de las constantes más llamativas de la $A P$, que proporciona un buen número de este tipo de epitafios. Gran parte de ellos se localizan en los primeros autores helenísticos y, en concreto, en los ligados al llamado por Reitzenstein (1893, p. 123 y ss.) «Círculo poético de Cos», caracterizados por su predilección por la descripción de una naturaleza idílica, que desemboca en la poesía bucólica de Teócrito: el VII 190 [20] atribuido a Ánite, el VII 192 [12] y 194 [13] de Mnasalces y el VII 200 [4] de Nicias ${ }^{18}$. Sin embargo, no existen paralelos inscripcionales al lado de esta afluencia literaria.

De estos animales se destaca el aspecto emotivo de lo que la mascota significa para su amo. Como en los epitafios dedicados a perros como mascota, el léxico seleccionado subraya esta vertiente afectiva, como se evidencia en el epigrama citado VII 190 [20] en que resalta con mayor fuerza la figura del

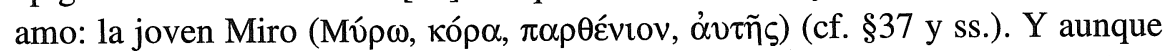
no está atestiguado que los insectos fueran considerados animales domésticos en la época de Ánite, pertenecían indudablemente al entorno cotidiano ( $v$. gr. la costumbre antigua de llevar prendedores de oro con forma de cigarras en el cabello; cf. Th. I 6). En cualquier caso, la investigación actual ha reconocido en el Naturgefühl helenístico - que ya Reitzenstein (1893, p. 133) mencionaba - un interés por todo tipo de animales, tanto exóticos como domésticos, incluyendo los insectos. De hecho, resulta sorprendente la elección por parte de Ánite de una pareja de insectos en lugar de uno solo - elección que resulta única en el conjunto de la $A P$-; ello conforma el motivo de la pareja que

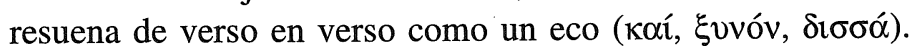

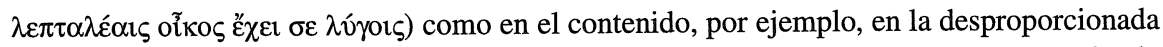
pretensión del mismo poeta de inmolar al felino sobre el cadáver de la perdiz, introduciendo así una poco oportuna alusión mitológica a Pirro y Aquiles. Lo mismo cabe apuntar a propósito del uso del mito de Acteón en la «respuesta» de Damocaris en VII 206. El elemento mitológico, que está dotado de una cierta función de epílogo en estos autores, parece introducir una alusión erudita que exige la participación de un lector cultivado capaz de reconstruir el «apex» del poema. De hecho, la introducción de doctrina mitológica en el poema de Simias constituye un rasgo de artificiosidad que se puede aducir para considerarlo posterior a Ánite; sin embargo, el peso de este argumento es limitado, ya que la contención en el tratamiento de la mitología en la poesía de Ánite parece no sólo un rasgo atribuible a su cronología temprana, sino también un rasgo personal de estilo.

${ }^{18}$ El propósito de Reitzenstein es mostrar la conexión de este grupo de poetas bucólicos estableciendo sus relaciones cronológicas a partir de las relaciones de imitación entre poemas de temática similar. Este autor concluye la prioridad cronológica de Ánite como «cabeza» de la escuela peloponesia, y aunque la validez de su argumentación es valorada críticamente por Gow-Page, estos autores no aportan ninguna hipótesis alternativa. 
Un aspecto adicional de la temática de insectos es su conexión con ciertos submotivos; el de la música se explica porque el «cantar» de estos animales eran considerado como símbolo de melodía dulce ${ }^{19}$. Este submotivo aparece muy difuminado en el poema de Ánite (óńdovr); en cambio, es central en los epigramas a insectos como pivote de la conexión entre animal-amo: en los poemas VII 192

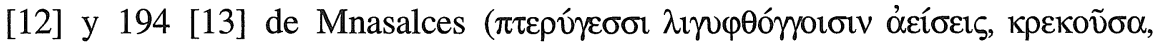

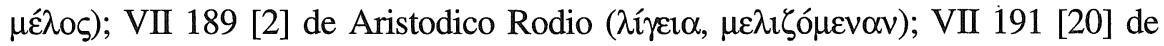
Arquias; VII 193 [2] de Simias; VII 195 [12] y 196 [13] de Meleagro; VII 197 [2] de Faenno; VII 200 [4] de Nicias y VII 201 [1] de Pánfilo aparece conectado el canto melodioso del insecto (casi siempre una ókpís, a veces una $\tau \varepsilon ́ \tau \tau \imath \xi{ }^{20}$ ) producido por las alas con la invitación al sueño reparador en un marco bucólico placentero. Mientras en el productivo desarrollo helenístico posterior de esta temática se recrea el motivo musical y el ambiente idílico campestre, ambos rasgos se hallan casi ausentes en Ánite (a pesar de que esta autora sí emplea este motivo en sus epigramas descriptivos y epidícticos; cf. Díaz de Cerio 1996, §§ 47-9) ${ }^{21}$.

Otro submotivo que aparece en otros autores es el del marco bucólico. El afecto por los animales se enmarca en el «redescubrimiento» y «revalorización idealizadora» helenística del entorno natural. En este contexto llega a nacer la

19 Así en $I l$. III 151, en Hes., Op. 583 o en la denominación platónica (Phdr. 262 d) oi

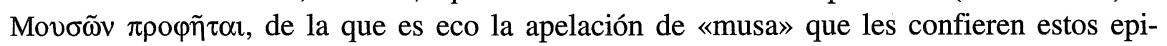
gramatistas; cf. VII 197 [2] de Faenno y VII 195 [12] de Meleagro.

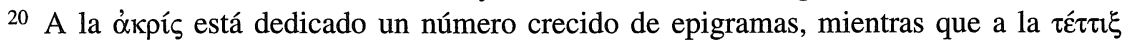
sólo están dedicados VII 201 y VII 213.

${ }^{21}$ La interpretación errónea del lematista del epigrama VII 202 [11] de Ánite a un insecto, cuando parece que se ajusta mejor a un ave (cuestión ya citada en $\S 5$ y 16 II) presenta en su descargo la indudable conexión de motivos e incluso léxica que se rastrea entre este epigrama del ave y los de insectos compuestos por imitadores de Ánite. En efecto, en VII 192 [12] - dedicado a una cigarra - Mnasalces integra el motivo de la sonoridad

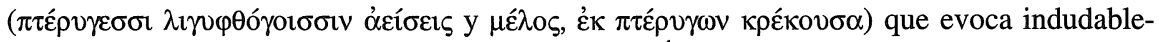

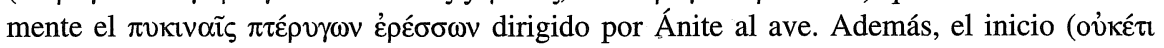
$\delta$ j́) con futuro refleja que Mnasalces ha imitado esta organización temporal del epigrama de Ánite, que también encontramos en epigramas posteriores dedicados a aves. Se plantea entonces si el propio Mnasalces, a pesar de ser contemporáneo, pudo malinterpretar como el lematista el destinatario del poema de Ánite, o si conscientemente compuso su recreación conservando motivos temáticos y voces léxicas e innovando en la selección del destinatario. Esta hipótesis requiere que se admita este flujo de influencias y esta relación cronológica entre Mnasalces y Ánite, pues Gow-Page, por ejemplo, estiman que el poema de Mnasalces parece más bien inspirado en el poema VII 189 [2] de Aristodico de Rodas, epigrama que Planudes atribuye también a Ánite, por lo que la cuestión parece estar lejos de una solución definitiva. En cualquier caso, la combinación de Mnasalces halló gran éxito, ya que esta asimilación de la temática musical a los insectos se registra en los compositores citados (el motivo de la música producida por las alas en VII 200 [4], 197 [2] y 201 [1] y el motivo general musical en VII 191 [20]; 193 [2]; 195 [12] y 196 [13]). 
poesía teocritea y, precisamente, se atribuye a Ánite una contribución no pequeña a ese desarrollo en su fase inicial. La importancia de la descripción del entorno vital de esta poetisa arcadia en sus poemas descriptivos y epidícticos es sobradamente conocida, por lo que resulta asombroso su silencio a este respecto en los epigramas dedicados a animales. En concreto, la descripción de un entorno agreste deleitoso caracterizado por una vegetación abundante, la sombra refrescante y el frescor de las aguas (obligado en Ánite, en los epigramas descriptivos y epidícticos; cf. Díaz de Cerio 1996: §§ 48 y 64) se registra, con diferentes combinaciones de estos motivos y con diversa intensi-

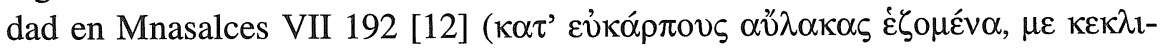

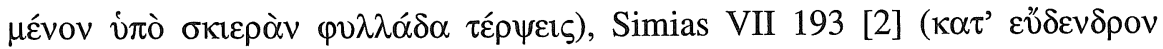

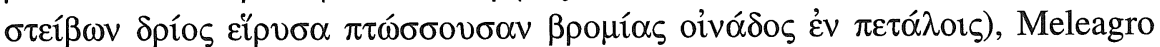

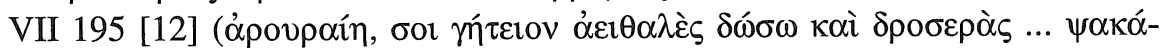

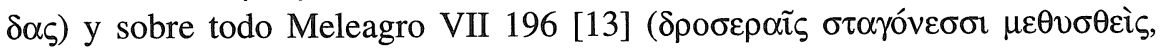

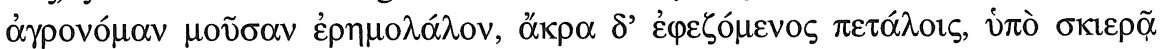

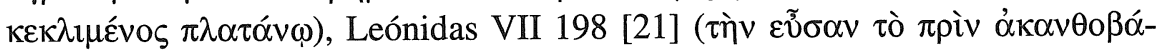

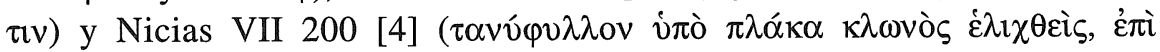

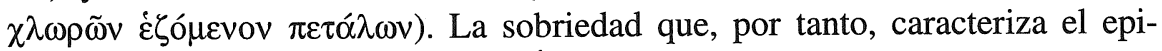
grama funerario sobre insectos de Ánite, lo distingue nítidamente de desarrollos posteriores y arroja luz - a mi juicio - sobre la relación cronológica entre Ánite y Mnasalces (cf. §52).

Un tercer submotivo, relativo a la conexión entre el insecto-mascota y su dueño, se concreta en la invitación al sueño que para éste constituye el canto

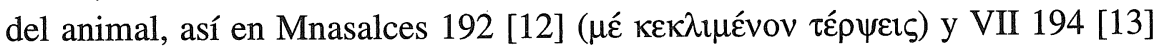

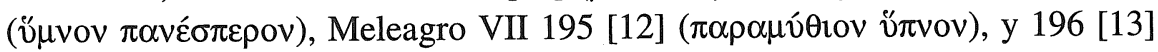

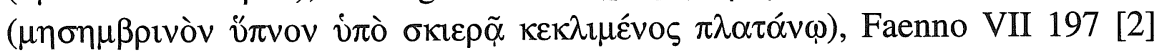
( $\beta \alpha \theta i ̀ v ~ v ̈ \pi v o v)$ ), Leónidas 198 [21] ( de nuevo que este submotivo se halla ausente en Ánite, a pesar de que esta autora incorpora un submotivo paralelo - la invitación al descanso en ese paraje idílico campestre - en sus epigramas descriptivos y epidícticos (cf. Díaz de Cerio 1996, §§ 64 y 76).

V) En el epigrama VII 215 [12] dedicado al delfín la selección léxica es la ligada a la descripción del entorno marítimo que caracteriza la vida de estos animales ${ }^{22}$. El texto parece describir el salto del delfín y su resoplido junto a los bordes del barco ${ }^{23}$. Resulta llamativo que a este animal, el más alejado de

22 El epigrama dedicado al delfín resulta difícilmente interpretable como inscripcional, especialmente en tanto en el propio epigrama no se alude a la cautividad o domesticidad del animal, a pesar de ser una especie conocida para los marineros.

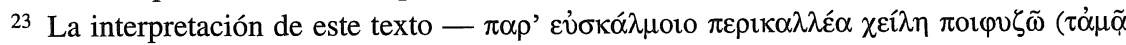

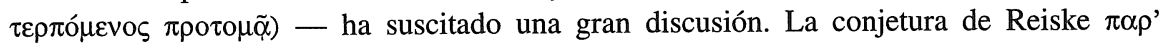


los examinados del centro de referencia humano, se le dote de caracteres hu-

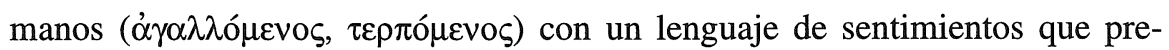
tenden acercar un animal en cierta medida más exótico y que contribuyen a elevar la emotividad de un epigrama de suyo propio poco susceptible para ello. Sin esta personificación, la misma temática es descrita en VII 214 [22] de Arquias y VII 216 [17] de Antípater de Tesalónica, que constituye un aviso gnómico a los navegantes ${ }^{24}$. El reflejo inscripcional de esta temática es inexistente.

16. Por tanto, la selección del animal determina dentro de una breve margen de elección, las cualidades que conforman el elemento tradicional del elogio. Estas cualidades se reiteran invariablemente en las series de epigramas que constituyen imitaciones con variación sobre la misma temática. El elogio del animal es en esa medida convencional frente al epigrama epitafial, mientras que en las citadas muestras inscripcionales y en los que no parecen constituir eslabones de una cadena de ejercicios literarios, como los epigramas de Ánite, el elogio, efectuado siempre desde la perspectiva de la relación emocional-utilitaria con el amo, posee vibraciones que parecen auténticas, muy en línea con el tono sentimental propio del Helenismo (frente a composiciones que muestran un dolor exagerado, como las de Agacías, Damocaris; en otras ocasiones, como en las composiciones de Meleagro, este elemento simplemente se suprime en un poema elegíaco que apenas guarda en común con un epitafio un tono doliente, pero que ni siquiera describe la muerte del animal).

17. Es posible rastrear una línea de evolución en los temas de animales de los que conservamos las versiones de autores de distintos momentos del $\mathrm{He}-$ lenismo y ello es particularmente aplicable al tratamiento de las aves y de los insectos, precisamente de los que carecemos de apoyo inscripcional. En estos epigramas se observa la práctica helenística de la variación en el ejercicio literario en una evolución hacia tratamiento más truculentos y en los que el elemento mitológico se desarrolla progresivamente.

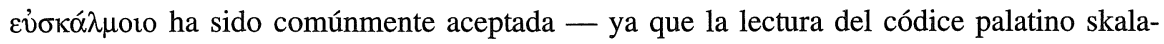

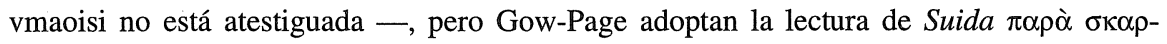
$\theta \mu$ oĩ . Así, los labios del barco $(\chi \varepsilon i ́ \lambda \eta)$ parecen señalar la $\sigma \tau \varepsilon i ̃ \rho \alpha$, o sea, la roda. No resulta fácil aquilatar si es esta parte de la proa la que presenta la figura de delfín como sugiere el texto de Pólux, I 85, o como la de un adjunto al espolón del barco (Suida); la elección de la lectura es difícil y en cualquier caso el entendimiento preciso de la expresión resulta notablemente mermado.

${ }^{24}$ Aunque Gow-Page (ad loc.) consideran que no se trata de la misma temática, no encuentro razones para negar la evidente relación entre estos epigramas, que exponen el mismo tema pero con diversos motivos. 
II1.4. La selección del animal y la funcionalidad del epigrama: ficción vs. inscripcionalidad

18. Es precisamente el género del epitafio a animales el subtipo de epigrama que más recelos ha despertado acerca de la ficción del género en época alejandrina. Esta desconfianza reposa sobre la que despiertan la propia $A P$ en conjunto y el libro VII en particular (cf. la síntesis de Waltz [1960, pp. 34-42] y el estudio de Th. Preger [1891], que constata que sólo 20 epigramas del libro VII pueden ser inscripcionales de los 44 en los que el autor lo reclama) ${ }^{25}$.

19. Aunque en el período helenístico es patente ya que numerosos epigramas funerarios no pueden ser inscripcionales, otros se continúan grabando sobre tumbas: coexisten inscripcionalidad y ficcionalidad (cf. Russell, 1990: 51), por lo que los autores de tránsito entre los s. IV y III, la llamada «primera generación de poetas helenísticos» (entre los que se incluye Ánite) conforman el quicio de esta cuestión, y la polémica sobre la inscripcionalidad sus epigramas cobra carácter decisivo. En el subgénero funerario, por la citada ampliación temática del epigrama y como testimonio de la literaturización del género surgen, junto a los epitafios elogiosos o satíricos de héroes y figuras ilustres del pasado -evidentemente no inscripcionalesde la colección simonídea, los epitafios dedicados a animales, que parecen consituir una «parodia» del género inscripcional.

20. El registro más antiguo de epigrama inscripcional dedicado a un animal que conservamos data del s. II a. C. (relieve de Memfis que representa una víbora), fecha excesivamente tardía para ser de peso en la discusión que afrontamos. De las etapas arcaica y clásicas no nos ha llegado ninguna muestra inscripcional de esta modalidad de epitafio y en la medida en que se conserva

25 Constituyen argumentos a favor de la inscripcionalidad que la arqueología haya certificado las representaciones dialógicas sobre sepulcros, que no son, como se pudo pensar, inventos literarios; la ocasional existencia de monumentos que constituyen el «tema» de descripción del epigrama, si bien la constatación de la existencia de un monumento específico no constituye una prueba formal de que el epigrama que lo describa sea inscripcional, pues varios poemas describen el mismo monumento (por ejemplo, la tumba erigida por Mero a sus insectos). En este sentido, la complementariedad entre epigrama y monumento permite que en el primero no figuren datos como el nombre del difunto, etc. que figuran en el segundo. En cambio, constituyen argumentos a favor de la ficcionalidad el crecido número de epigramas dedicados a hombres ilustres del pasado, escritores, figuras mitológicas (cf. Waltz, 1969, p. 63, n. 4); la existencia de epigramas excesivamente retóricos o enigmáticos; los epigramas compuestos por diversos autores a un mismo destinatario (aunque poco frecuentes, sí existen diversos epigramas que forman parte del mismo epitafio como $A P$ VII 327 y 328; cf. $G V$ 1915) y el tratamiento de un mismo tema por diversos autores. 
la colección simonídea en la transmisión palatina y planudea, en ella es un subtipo desconocido: la temática animal parece una innovación helenística y, de hecho, se ha asociado para siempre al nombre de Ánite (cf. Del Barrio, Guarducci, Körte, Paton, Reitzenstein, Trypanis, Waltz, Wilamowitz, etc.).

21. En el caso de los epigramas dedicados a animales transmitidos por la $A P$ y $A P l$ las opiniones se condensan en dos extremos:

I) La opinión de Reitzenstein (1893, pp. 126-7; 1894, p. 265) es ilustrativa de la desconfianza que producen estos epigramas: «wer nicht von selbst empfindet, daß Anytes Gedichte für das Buch verfaßt sind, der mustere ihre Epighramme auf tote Lieblingtiere und vergleiche, wie dieselben schon bei den nächsten Nachahmern wieder zu Epitymbien werden, wie bei Mnasalces». Este autor concluye de su análisis de los poemas que el hallazgo de este subgénero se debe o a Ánite o a Mnasalces: «die Übertragung derartiger Stoffe auf die Forme de Grabauschrift scheint die villkürliche That eines für das Buch Dichtenden. Mnasalkas oder Anyte hat dies erfunden». Esta interpretación sobre los epigramas de Ánite ha constituido la opinión dominante sobre el subgénero de epitafios dedicados a animales.

II) La opinión contraria, liderada por Wilamowitz (1924, p. 137, n. 8), aduce los paralelos inscripcionales en defensa de la inscripcionalidad de los poemas de Ánite dedicados al caballo y al perro: «eine wirkliche Grabschrift für ein Pferd VII 208 auch das Gedicht für einen Hund bei Pol. 5.48 wird auf dem Graben gestanden haben. Inschriftliche Analogien fehlen nicht». En una línea similar, constatan Gow-Page (1965 2, p. 91), cuando menos, la formulación inscripcional de estos poemas de Ánite: «the animal epitaphs are so written that, given a grave, they could be inscribed on one. If therefore they were not intended for that purpose they cast some doubt on the bona fides of A.'s other epigrams, all of which are similarly phrased as though for inscription». La opinión de estos autores varía de epigrama a epigrama con diversos matices.

22. La opinión moderada de Wilamowitz y Gow-Page contiene un punto de interés, a saber, admite la diversidad de grado. Al aplicar esta opción a los epigramas en examen se registra la siguiente gradación:

I) epigramas de inscripcionalidad probable:

Los epigramas dedicados al caballo y al perro han podido ser inscripciones reales para tumbas de estos animales domésticos, erigidas por sus amos como muestra de su cariño. Un sólido argumento a favor de su posible inscripcionalidad lo constituyen sus paralelos temáticos inscripcionales ya citados. No es posible demostrar que estos poemas fueron grabados, ni tampoco su contrario, pero si se puede argumentar que sí pudieron ser grabados ${ }^{26}$ Se plantea entonces si existen

${ }^{26}$ Cf. G. Herlinger, 1930, p. 39. Contamos con testimonios literarios que consignan esta costumbre de enterramiento de animales domésticos: Thphr., Char. 21.9; D.S. XIII 82 y Ael., VH VIII 4. 
datos internos a estos poemas que hablen de su inscripcionalidad, por ejemplo, la mención de la tumba, que es clara en el primer epigrama ( $\tau$ ó $\delta \varepsilon \mu \nu \tilde{\eta} \mu \alpha{ }^{27}$ ), pero está ausente del segundo; sin embargo, el cotejo de los epigramas inscripcionales dedicados a perros permite concluir que la ausencia de mención a la tumba no es un criterio seguro, pues la mención del monumento aparece consignada de forma aleatoria ${ }^{28}$.

II) epigramas de inscripcionalidad discutida:

Entre los epigramas cuya inscripcionalidad se halla sujeta a discusión hallamos el dedicado al ave. Puede resultar llamativo que se erija un monumento o simplemente que se consigne en una tablilla la muerte de un animal tan insignificante como un ave muerta por un felino. El hecho de que el animal sea un pájaro doméstico facilita que en un entorno emotivo como el de la poetisa de Tegea, con ese gusto por lo íntimo y afectivo, un suceso como éste, propio de la atmósfera familiar y cotidiana, suscite una composición poética, como además lo sugiere el tono personal del poema, en el que la poetisa desempeña el papel de dueño del animal y «encargante» del epigrama (cf. apdo. II2). La consignación del mismo en una tablilla, como expresión del afecto de una joven o de un niño no es impensable, pero carece de argumentos a su favor como sugieren Gow-Page (1965, p. 91): «it is possible, we imagine, that a poet sometimes composed for a child an epitaph on a dead pet which might be written out and affixed to a memorial of some less permanent material than marble or stone; ...» Pero no existen, de hecho, paralelos inscripcionales de epitafios reales que puedan sustentar esta interpretación. Su inscripcionalidad no es sólo, como en el caso anterior, indemostrable, sino, además, menos probable.

III) epigramas de inscripcionalidad improbable:

Que un insecto haya sido merecedor de un epitafio y de la erección de un monumento funerario repugna nuestra mentalidad actual; sin embargo, la misma argumentación que se ha efectuado a propósito del ave es aplicable al insecto si se admite que el insecto era considerado un animal doméstico. La predilección de los niños por esta clase de seres es una constante cultural y no es chocante que hayan podido ser retenidos en cautividad como mascotas: los epigrama VII

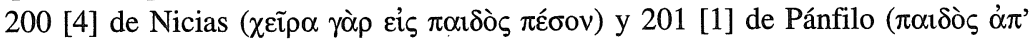

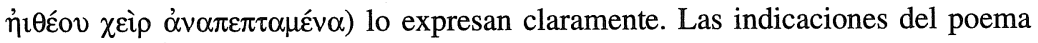
atribuido a Ánite en relación a este punto son, como corresponde a su estilo, muy vagas. De hecho, Gow-Page (1965, p. 91) conectan la discusión de la inscripcionalidad con la de la cautividad: «most of the insects are expressly said to have

27 Cf. Wilamowitz, 1924, p. 16 y Gow-Page, 1965, p. 95: «it seems unlikely that a horse so killed would have a distinguishable grave, but if, as the form suggests, the epigram was intended for inscriptional purposes it might have been for a commemorative stele. The form, however, may be misleading».

${ }^{28}$ El estudio de la mención del monumento funerario, cuya imbricación en la discusión sobre inscripcionalidad es patente, queda reservado para un trabajo aparte (cf. n. 2). 
been kept in the house, but it is a far cry from a charger to a grasshoper; it is not easy to believe that the epigrams were all carved on tombstones, and doubts are increased by similar poems on creatures which did not die in captivity». Algunos poemas meleágricos (como el VII 200 [4] de Nicias), incluso, relatan la cautividad y no la muerte, aunque desde el punto de vista formal (la estructura

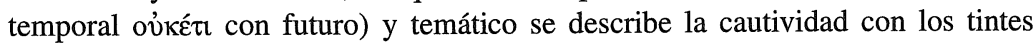
trágicos que se asocian habitualmente a la muerte en los epigramas de humanos y animales ${ }^{29}$.

La interpretación del delfín como animal doméstico resulta muy difícil de apoyar, y no constituye tanto el obstáculo a la inscripcionalidad el indudable exotismo del animal como el hecho de que no se menciona ninguna persona relacionada afectivamente con el animal. La indicación del párrafo anterior acerca de los animales que no mueren en cautividad puede aplicarse a este epigrama cuya inscripcionalidad es rechazada prácticamente de forma unánime. Este poema y los que reproducen su temática parecen constituir ejercicios literarios, en gran medida por su escaso respeto a los elementos del epigrama funerario canónico (carecen de indicación del encargante y del monumento funerario).

23. La gradación en la probabilidad inscripcional de los epigramas a animales de Ánite no ha de encorsetarse en generalizaciones globales que sean poco respetuosas con la realidad del análisis. La formalización de los resultados nos conduce a las siguientes puntualizaciones:

- no conservamos atestiguación de inscripcionalidad de los epigramas epitafiales de Ánite (ni de los de otros subtipos epigramáticos), por lo que esta autora pudo componer tales poemas con propósito o inscripcional o literario; en este sentido, las pruebas formales que atañen a sus epigramas a animales no son diversas de las que atañen a sus epitafios dedicados a humanos, a pesar de que éstos sí se consideran inscripcionales y aquéllos no. De los otros autores melágricos tampoco se nos han transmitido epigramas extraídos de inscripciones, ni compuestos para humanos ni para animales ${ }^{30}$;

29 Quizás en este sentido se ha de interpretar la opinión de Reitzenstein, quien apuntaba en respuesta a la cuestión de Susemiehl sobre si éste es un poema completo, que la forma inscripcional desaparece porque el tema debe expandirse a la medida de un poema literario (aunque el tema sea más propio de una canción elegíaca que de una inscripción).

${ }^{30}$ Un caso excepcional es el VII 567 atribuido a Leónidas, sobre el que el corrector

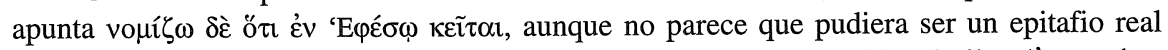
(cf. para mayor detalle Gow-Page, 1965, p. 328). Una información similar ( $\varepsilon$ ' $E \varphi \varepsilon ́ \sigma \omega$

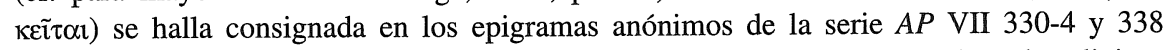
dedicados a naúfragos; los epigramas de este tenor se explican por la exigencia religiosa griega de dar sepultura a los cadáveres aun cuando se desconociera su identidad, como podía suceder a los cuerpos arrojados por el mar tras un naufragio. 
- la forma lingüística inscripcional de los epigramas: los epitafios de animales no se distinguen ni de los restantes de Ánite ni de los inscripcionales (cf. §§ 27-29) salvo quizás en una mayor elaboración del lenguaje, difícilmente mensurable conforme a criterios objetivos;

- la temática de animales sólo permite argumentos con paralelos inscripcionales - y éstos ya muy tardíos - en poemas como los dedicados al caballo y al perro, por lo que su fuerza argumentativa en relación a la dirección de las influencias de la realidad a la literatura o viceversa es poco sólida. En relación a animales alejados de la esfera de la vida cotidiana como aves e insectos, aunque la cautividad-domesticidad es posible, el hecho de que constituyan tema de imitación parece sugerir que se trata de un puro ejercicio literario. Cabe preguntarse si los dos epigramas de Ánite eran inscripcionales y sobre ellos varían los imitadores posteriores (Simias, Mnasalces y Nicias, con Pánfilo y Faenno y posteriormente Meleagro, Timnes, Damocaris, Agacías, etc.), de la misma manera que los epigramas ficticios dedicados a humanos imitan ostensiblemente los epitafios reales originarios (cf. L. Weber, 1917).

24. Habría que concluir en relación a lo dicho que en los epigramas funerarios a animales de Ánite se bascula entre creaciones con formulación inscripcional, con paralelos inscripcionales de época arcaica y clásica - del tipo del caballo guerrero - , y creaciones evidentemente literarias, como la del delfín, que no puede considerarse ni siquiera formalmente un «epitafio» sino un poema de carácter elegíaco compuesto a la muerte - ficticia o real, es irrelevante - de un animal, y que carece de todo paralelo inscripcional, incluso de época imperial o posterior.

25. La opción de que la poetisa escribiera únicamente epigramas inscripcionales o epigramas ficticios (sentido en el que se pueden interpretar las palabras de Gow-Page extendiéndose a otros subgéneros) no se ha de plantear de forma necesaria, como se ha hecho habitualmente. Si de forma paralela se siguen escribiendo epigramas inscripcionales junto a los evidentemente ficticios durante todo el helenismo hasta entrado el imperio, de igual manera un autor puede cultivar ambas formas funcionales del género (con un marcado calco de la formulación inscripcional, que es la única tradicional que Ánite encuentra como precedente).

26. La opinión generalizada - especialmente en trabajos que abordan el epigrama helenístico con carácter general - , de que los epigramas a animales de Ánite son ficticios se comprende como un expediente para resolver esta 
compleja cuestión sobre el apoyo de que alguno de estos epigramas es claramente ficticio; mientras que alguno de ellos sea inscripcional es indemostrable en tanto no aparezca el documento epigráfico: es decir, no existe ninguna prueba formal que apoye su inscripcionalidad. El citado deseo de «uniformizar» el carácter de los poemas explica que se favorezca la opción de la ficcionalidad, aunque tampoco ésta pueda ser probada.

\section{II1.5. Consignación formal del nombre del difunto}

27. Existen cinco formas básicas en las que puede aparecer consignado el nombre del difunto (cf. Guarducci, 1974, p. 147):

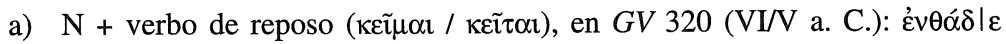

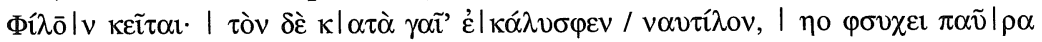
$\dot{\alpha} \mid \gamma \alpha \theta \dot{\alpha}$.

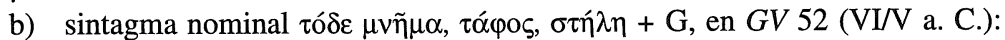

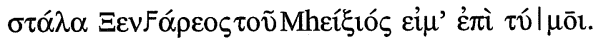

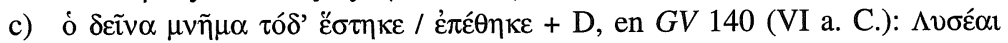

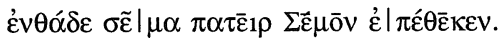

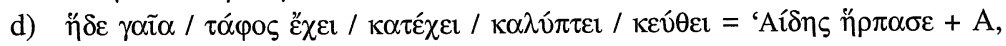

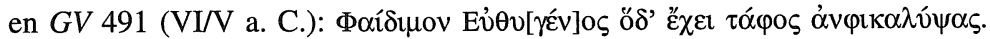

e) V + fórmula de saludo, en IG II/III 7861 (fines del II a. C.): $\Delta \eta \mu \eta ি \tau p \varepsilon \varepsilon$

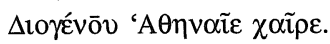

28. Las variantes formulares señaladas se encuentran representadas en los epitafios de Ánite a animales:

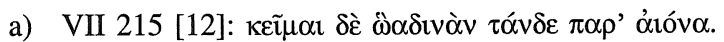

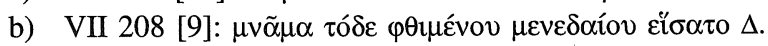

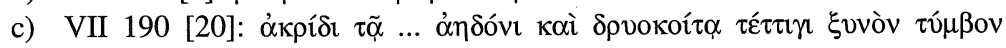

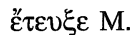

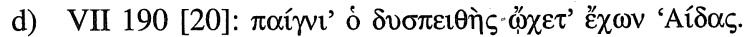

e) Pol. V 48 [10]:

29. La interpretación de esta formulación cobra su sentido en el cotejo de la de los otros elementos epitafiales - la mención del encargante (cf. 2.3), del propio monumento y de las circunstancias de la muerte - , porque todos ellos se imbrican en fórmulas consagradas por el uso. La tabulación presentada permite advertir que la innovación de Ánite con respecto al canon epitafial tradicional que supone la incorporación de muertes de animales es pareja a un respeto riguroso por la consignación del elemento central de todo epitafio la identificación del difunto - y de la formulación para ello empleada: la fidelidad formal contrapesa la innovación temática en una autora que opera 
esa innovación creadora en un género hasta entonces guiado exclusivamente por las necesidades sociales.

\section{II2. El erector}

\section{II2.1. La mención del encargante, del familiar y de la patria}

30. Panorama de la tradición previa. En el epitafio tradicional, además de la pervivencia de la memoria del difunto, se pretende la pervivencia del personaje que erige el monumento y graba o hace grabar el epigrama en él inscrito. Esta costumbre se advierte en epigramas inscripcionales de época arcaica

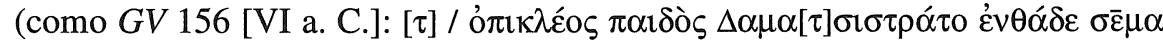

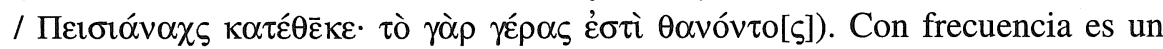
familiar el que asume la función de encargante, por lo que se funde en una sola figura los dos elementos del epitafio: el erector y el familiar, que en alguna ocasión pueden aparecer disociados. A ello se suma que la mención del padre o del patronímico, en concreto, constituía, además, un medio de identificación del difunto, sustitorio del nombre propio: como en $G V 66$ (VI /V a. C.): $\tau \grave{\alpha} \varsigma$

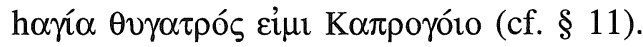

31. Panorama en los epitafios de Ánite dedicados a humanos. Con frecuencia, en el epitafio dedicado a individuos de época helenística es un familiar

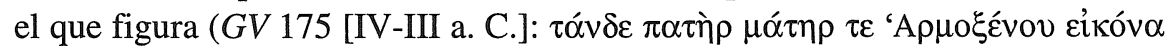

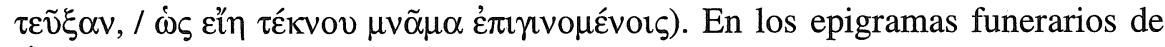
Ánite hallamos esa figura familiar: el padre en el epitafio del guerrero (VII

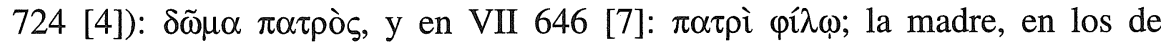

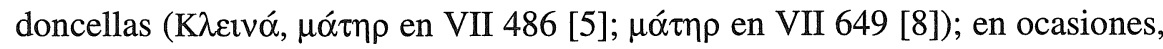
la insistencia en la presencia del familiar ha hecho suponer que quizás el monumento los reproduce en el relieve: la madre (cf. Gow-Page) en VII 486 [5], el padre en VII 490 [6]. En los autores coetáneos de Ánite se encuentran composiciones como las primitivas, que consignan el patronímico como mero rasgo de identificación del difunto (Nossis VII 718 [11), y otras que prescinden de él por completo (VII 284 [30] de Asclepiades); en conjunto, tales epigramas transmitidos por fuentes literarias muestran una llamativa ausencia de este elemento propio del epigrama inscripcional.

32. Panorama en los epitafios de Ánite dedicados a animales. En el caso de los epigramas dedicados a animales no es posible la mención de un «familiar», que es sustituido, como en el caso de los esclavos, por el amo; así se dota al animal, desprovisto de individualidad por sí mismo, de identidad por medio de la referencia al dueño, con las siguientes variantes: 
I) nombre propio del amo: como en el epigrama sepucral canónico, se menciona el nombre del presunto encargante, en este caso, el amo, así el guerrero $\Delta \tilde{\alpha} \mu \mathrm{t} \varsigma$ en VII 190 [20] o la joven Mero, en el de la cigarra y el saltamontes, cuya presencia en el epigrama se evidencia con más fuerza de lo habitual (cf. §15.IV);

II) el amo se identifica con el emisor: especialmente emotivo es el poema del ave, en el que es la propia poetisa quien asume la función de «encargante», pues la subjetividad de la autora se trasluce en su involucración personal en el poema: $\mu \varepsilon$. Es el único de los epigramas en los que figura la poetisa en esta función;

III) ausencia de mención humana: cuanto más se aleja del centro doméstico de familiaridad el animal al que se dedica el epitafio, tanto más difícil se hace la mención del ser humano ligado a él (v. gr. en Pol. 48 [10] no interviene ningún ser humano, aunque se sobreentiende; en el epigrama dedicado al delfín no es posible ni siquiera esta última opción).

33. Por tanto, la variedad representativa de este elemento tradicional en los epigramas a animales de Ánite corre pareja con la fidelidad a otros elementos del epigrama canónico:

- el encargante-familiar, transmutado en amo, se conserva en los poemas de corte tradicional y se omite en los que se aproximan más a elegías que a epigramas funerarios; este rasgo formal de presencia o ausencia está ligado temáticamente a la domesticidad / no cautividad del animal;

— en ningún caso se desdobla la figura del personaje que erige el monumento;

- no se precisa la mención de la patria (salvo por otros motivos, en el epigrama de Pol. 48), que constituye un dato superfluo, carente de funcionalidad en este tipo de epigramas. Ánite sólo conserva la mención de la patria en el epitafio al guerrero, que es el más fiel al canon de su corpus; sin embargo, el afán por el detalle biográfico de época romana proporciona ejemplos de epigramas reales a animales que sí detallan este dato $(\Lambda \varepsilon \sigma \beta 1 \alpha \kappa \tilde{\eta} \iota ~ \beta \omega ́ \lambda \omega r$ vं $\varepsilon \theta \dot{\eta} \kappa \alpha \tau$, en GV 309 (I-II d. C.), ya citado en $§ 15 . I I b)$.

\section{II2.2. Expresión del dolor del familiar y tema de la pérdida}

34. Panorama de la tradición previa. Las celebradas brevedad y «contención» del epigrama arcaico refrenan las mánifestaciones de duelo. Así, este motivo está muy poco desarrollado en los epigramas inscripcionales que hemos contemplado.

35. Panorama en los epitafios de Ánite dedicados a humanos. La conocida influencia de tragedia y retórica en el epigrama helenístico se advierte en una manifestación más expresiva de dolor por la pérdida del fallecido, con su correspondiente reflejo en el monumento artístico (cf. Webster, 1964: 20) ${ }^{31}$.

31 Cuando se invita al caminante a leer el epitafio, se le exigen no sólo la lectura y la

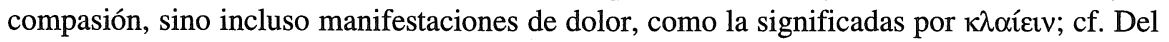
Barrio (1992, p. 24). 
Con frecuencia la expresión de duelo se efectúa por medio de fórmulas fijas

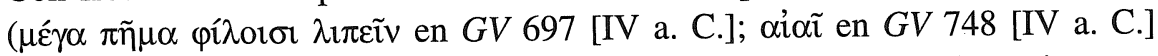
y VII 488 de Mnasalces). Ilustran este aumento de emotividad los epigramas de Ánite dedicados a doncellas, que explotan el tema helenístico de la desolación que causa en los padres la muerte prematura de los hijos.

36. Panorama en los epitafios de Ánite dedicados a doncellas. En los epigramas de Ánite a doncellas la carga emotiva se advierte en la descripción del dolor que en los familiares causa la muerte, en ocasiones, con tintes trágicos, como en los lamentos maternos de VII 486[5]: غ́ßó $\alpha \sigma \eta$, y $\alpha \gamma \kappa \alpha \lambda \varepsilon ́ o v \sigma \alpha$ (que en la interpretación de Jacobs describe el rito de la conclamatio, si bien Gow-Page apuntan que ésta es una costumbre más romana que griega), o en

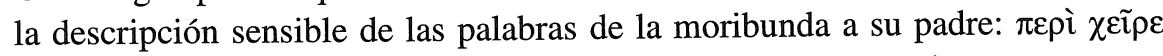

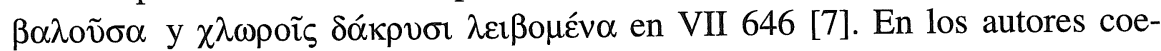
táneos de Ánite se halla el mismo tipo de descripción del dolor de los familiares en lo que parecen ser, como en el citado poema de Ánite, escenas del rito funerario (cf. VII 487[6] de Perses) o descripciones del propio monumento (cf. VII 730 [7] de Perses).

37. Panorama en los epitafios de Ánite dedicados a animales. En los epigramas a animales el vínculo familiar se halla sustituido por la relación amomascota (cf. 15.II y IV, 16 y apdo. 2.1). Las expresiones de dolor son más evidentes cuanto menor es la utilidad del animal, es decir, cuanto más patente es su carácter de «mascota», y ello tanto en los epigramas inscripcionales (cf. el epigrama al perro de caza de $\$ 15$.IIa con el epigrama a la perra-mascota de 15.IIb) como en los de Ánite. En efecto, en VII 190 [20] la poetisa describe

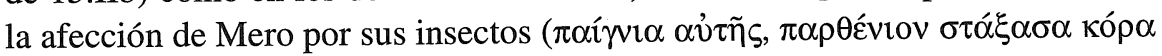
$\delta a ́ k \rho v)$ con una sensibilidad no menor que aquella con la que describía el afecto de los padres por sus hijas en los epitafios citados; es la disimetría entre la expectativa del género y de la función la que da lugar a la interpretación de ficcionalidad.

38. El epitafio del ave, de gran emotividad por la involucración de la poetisa como emisor (cf. 32.II), constituye - sea real o ficticio - un eslabón entre los epitafios dedicados a animales domésticos cuya muerte supone una pérdida para el dueño, de los que constituyen meros ejercicios literarios. En cambio, en el otro extremo, en el epigrama del delfín la ausencia de un ser personal que actúe como amo priva de esa dimensión de dolor por la muerte del animal (aunque la estructura emotiva de las «palabras del moribundo» compensa esta carencia).

39. Es difícil calibrar en qué medida en los epigramas a estos animales, el dolor se expresa como un sentimiento convencional más que como eco de una 
afección verdadera. Ya en los epigramas helenísticos a humanos, el elogio del difunto - aun en relaciones personales muy próximas - parece guiado por un canon más que por la situación individual que se describe (v. gr., los elogios a las esposas y relaciones esclavo-amo; cf. Waltz, 1960, pp. 41-7, quien atribuye esta convencionalidad a que el poeta es el porte-parole de los familiares y no expresa ya sus propios sentimientos).

40. Es preciso remarcar, no obstante, que las expresiones de dolor por los animales son más emotivas en los epigramas de Ánite que en sus contemporáneos, como el paralelo de Leónidas de Tarento VII 198 [21], por ejemplo, al saltamontes de la joven Filainis, o los de Mnasalces VII 192 [12], etc., en los que no se registran expresiones de dolor. Un tono similar al de Ánite encontramos en los epigramas inscripcionales a perros domésticos ya citados,

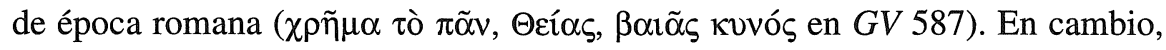
en los autores posteriores - Meleagro, Damocaris, Agacías - el excesivo énfasis en el dolor aproxima el epigrama a una composición irónica.

\section{II2.3. La expresión formal del encargante-familiar}

41. Panorama de la tradición previa. Entre las fómulas de epitafios arcaicos privados consagrados, el erector (sea público, cf. $G V$ nr. 43 y ss., o privado) suele aparecer en fórmulas transitivas consignado en $\mathrm{N}$ con dos variantes ${ }^{32}$ :

1) el monumento aparece en A y el difunto en $\mathrm{D}$; el verbo es de dedicatoria:

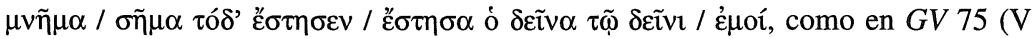

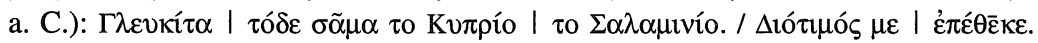

2) el monumento aparece en $\mathrm{L}$ y el difunto en $\mathrm{A}$; el verbo es de disposición:

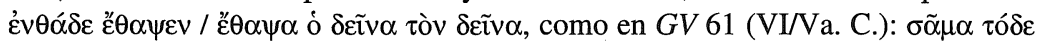

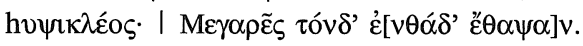

En ambos casos, estas formulaciones transitivas exigen como sujeto al erector del monumento o el familiar que figura como tal. Ello no quiere decir que en fórmulas diversas no sea posible consignar el nombre del erector, sino que las fórmulas citadas son las que lo presentan como punto informativo obligado y central.

42. Panorama en los epitafios de Ánite dedicados a humanos. Las variantes incluyen:

- mención explícita de que el familiar es el erector por medio de una fórmula

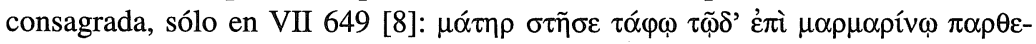

${ }^{32}$ Los ejemplos citados corresponden, respectivamente, a los tipos I.2 (1988, p. 40 y ss.) y I.3 (p. 75 y ss.) de Peek. 


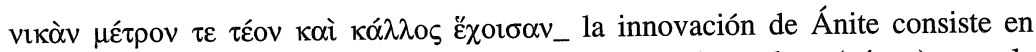

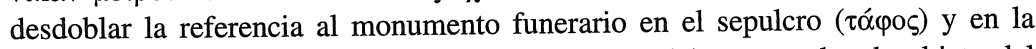
imagen comemorativa de la fallecida, que ocupa el lugar regular de objeto del verbo de colocación ( $\pi \alpha \rho \theta \varepsilon v \imath \kappa o ̀ v)$;

- mención explícita del familiar, pero se reconstruye sólo indirecta e hipotéticamente que éste deba de identificarse con el erector del monumento: VII 490 [6], VII 486 [5], VII 646 [7] y VII 724 [4] (cf. apdo. 2.1). En ningún caso se registra la ausencia de este elemento.

43. También otros autores contemporáneos de Ánite citan casi sistemáticamente algún familiar, en relación o no con la erección del monumento, con la siguiente distinción: generalmente la consignación del padre constituye rasgo de identificación del difunto (cf. apdo. 2.1); la de otro familiar posee, en cambio, funcionalidad emotiva (la madre en VII 487 [16] de Perses, el propio poeta como amigo del difunto en VII 11 [28] de Asclepiades, o unos marineros en VII 267 [15] de Posidipo). Uno de los casos excepcionales en los que erector del monumento es distinto del familiar es VII 710 [1] de Erinna (el

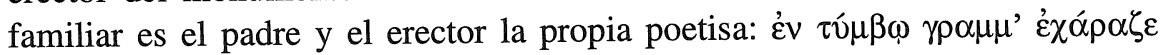

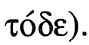

44. En autores posteriores, con paralelos inscripcionales, se consigna como figura de erector/familiar el amo en sepulcros de nodrizas o esclavos, lo cual origina una cierta «inversión» de la funcionalidad commemorativa primera del epitafio, pues el elogio se desplaza del difunto al erector, como en $A P 179$, de

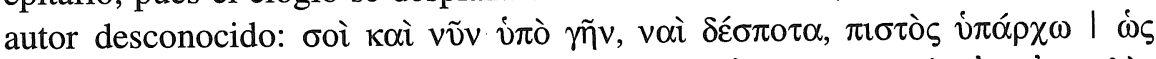

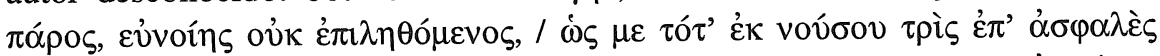

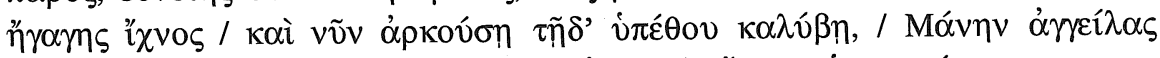

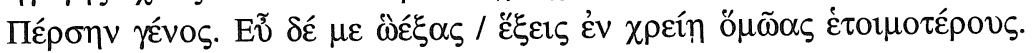

45. Panorama en los epitafios de Ánite dedicados a animales. Se reproducen las mismas variantes mencionadas en $\S 41$ : menciones explícitas en VII

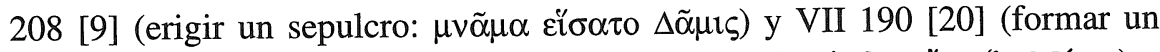

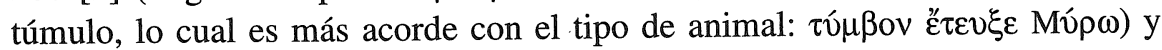
ausencia de indicación relativa a la erección del monumento en los restantes epigramas.

46. La consignación del erector en los poemas dedicados a animales se recoge en dos grupos, dependiendo de si simplemente se menciona un familiar (v. gr. Mnasalces 192 [12], Meleagro 195 [12] y 196 [13]) sin conexión con el monumento (es decir, para expresar su identificación y el tema del dolor por la pérdida), o de si se menciona el familiar en conexión con la erección del monumento (Faenno VII 197 [2], Mnasalces 194 [13], Leónidas 198 [21], Agacías 204, Melagro 207 [65], Antípater de Sidón 209 [57], Timnes 211 [5], 
Marco Argentario 364 [21]). En ningún caso en un epitafio de animal se desdoblan familiar y erector.

Son muy frecuentes en la $A P$ los epitafios de esta época tardía que no consignan ni la referencia al monumento ni al familiar, por lo que su lejanía del canon epitafial es muy marcada (v. gr.: Simias VII 203 [1], Aristodico Rodio VII 189 [2], Arquias 191 [20], 193 [2], 213 [21]y 214 [22], Timnes 199 [4], Nicias 200 [4], Pánfilo 201 [1] y Antípater de Tesalónica 216 [17]). En cambio, no está instanciado el subtipo que combina la mención explícita de erección del monumento pero no del familiar que la promueve.

47. Por tanto, la consignación del familiar en relación a la expresión del «dolor por la pérdida», es prácticamente obligada, pues la ausencia de involucración de un erector-familiar despojaría al epigrama de animales de un factor nuclear. Si en los epitafios arcaicos el dolor apenas se mencionaba en la fría y objetiva información y se introduce como un desarrollo posterior favorecido por el sentimentalismo helenístico, en los epigramas de animales constituye un factor clave y ello por dos motivos, primero porque es el amo el que constituye el punto de referencia del animal según lo apuntado en el apdo. II.1, y porque la muerte del animal queda desprovista de significado si no es como eco de esa esfera íntima personal que lo detiene al mero nivel del sentimiento, a diferencia de la de los humanos, que está siempre dotada de un trasfondo trágico.

\section{CONCLUSIONES}

\section{En relación al elemento «consignación del difunto»:}

- como factor de diferenciación con respecto a los epitafios a humanos, la mención del difunto no es obligada en los epigramas de animales, incluso puede constituir una alusión vaga a la tipología del animal. Esta innovacion sustancial respecto del canon tradicional deriva de que el animal «difunto» carece de individualidad propia si no es por referencia a su amo, y ello tanto en Ánite como en los autores coetáneos y posteriores (cf. 12);

- en los epigramas de Ánite, además, la identificación de la especie del animal, obligada en los epigramas inscripcionales, sólo se efectúa de forma explícita en los dos epigramas que más visos poseen de inscripcionalidad por respetar el canon tradicional y por la propia selección de animales domésticos del entorno del hombre: en los poemas dedicados al caballo y al perro (y el de insectos); en los restantes poemas la identificación del animal se deja a la reconstrucción del receptor;

- el motivo tradicional del elogio del difunto es obligado en los epigramas de animales siguiendo la tendencia que muestran los epigramas helenísticos dedicados a humanos frente a la contención del epitafio tradicional; el elogio se 
basa en la relación amo-mascota y depende directamente del tipo de animal, por lo que las cualidades del difunto se reiteran invariablemente en las series de epigramas que constituyen imitaciones con variación sobre la misma temática (1317).

\section{En relación al elemento «consignación del erector»:}

- en los epigramas de animales se funden las figuras del erector y del familiar en la del amo como una innovación derivada del tipo de «difunto»; Ánite refiere la erección del monumento con fórmulas tradicionales, o bien innova en ocasiones obliterando ese elemento tradicional (cf. 30-3 y 41-7);

- el motivo del dolor por la pérdida del difunto ofrece en Ánite ese mayor grado de emotividad que encontramos en los epigramas helenísticos a humanos. En contraste con autores tardíos, sin embargo, el sentimiento de dolor - en modo alguno efectista ni desmedido y descrito como un afecto proporcional a la vinculación del amo con el animal -, es sugerido más que explicitado (cf. 34-40).

50. Ánite ofrece, pues, muestras del desarrollo naciente del subtipo de epitafio de «animales», que respetan el canon de elementos tradicionales (caballo, perro e insectos) y otras que prefiguran el desarrollo posterior de este subtipo hacia composiciones de carácter elegíaco (ave y el delfín); cf. $17{ }^{33}$.

\section{Inscripcionalidad}

Desde la perspectiva temática Ánite trata animales que parecen haber podido figurar en inscripciones de su propia época (aunque la escasez de datos no permite sustentar formalmente esta hipótesis). En este sentido es relevante el comentario del epigrama $G V 1365$ que refleja la «excepcionalidad» de las inscripciones para animales («no te rías por ser la tumba de un perro; fui llorado ...»). Al tiempo, esta autora presenta animales no domésticos que parecen haber constituido un tema muy apreciado en el período helenístico, por el número de variaciones de distintos autores que sobre ellos nos han llegado (particularmente, de insectos y de delfines). La cuestión es irresoluble por la falta de datos; lo más respetuoso con los hechos parece ser aceptar una diversa gradación en la probabilidad inscripcional (cf. 18-26). La posibilidad que se aporta en este trabajo reside en conectar la probabilidad derivada de la temática animal seleccionada con el mayor o menor respeto a la formulación tradicional del epitafio, pues se observa que Ánite - dentro de su tendencia conservadora en relación a la formulación - respeta el canon con mayor fidelidad en los epitafios de animales «domésticos» de los que conservamos registro inscripcional, pero imita o desfigura algunos o varios elementos (incluidos la mención

33 Estas conclusiones han aún de sumarse a las que afectan a cuestiones de organización estructural del epitafio para adquirir una visión global, y en este sentido, más auténtica, del desarrollo del tipo epitafial en manos de esta autora. 
de la tumba con un desarrollo mayor del elemento de las circunstancias de la muerte y de la doctrina mitológica) en los que derivan luego hacia poemas elegíacos (tipo delfín) (cf. §§ 11 y 18-26).

\section{El «color» bucólico y la ubicación cronológica de Ánite}

Ánite inicia ese mundo intimista de resonancias privadas, aún contenido en esta autora y que se desborda en los cultivadores del mundo jonio. El propio género de epigramas a animales encuentra su explicación en el gusto por una naturaleza idílica, rasgo definidor de la sensibilidad helenística. Por ello tiene interés que este elemento temático que Ánite perfila nítidamente en sus epigramas descriptivo-epidícticos aparece ensordecido en los epigramas a animales, que se prestaban especialmente para ello; y ello es tanto más llamativo cuanto este motivo se encuentra casi obligadamente en los demás epigramatistas posteriores a esta autora. A mi juicio, este hecho contribuye a iluminar la oscura cuestión de la dirección de influencias entre Ánite y Mnasalces y a la aportación que a cada uno de ellos se atribuye en la gestación de este subgénero.

En efecto, el examen de los epigramas de ambos autores sugirió a Reitzenstein que éste se inspira en aquélla, y precisamente el estudio de los submotivos «bucólicos» permite apoyar la tesis de este autor - aceptada también por Wilamowitz - frente a la actitud crítica de Gow-Page: Ánite presenta una innovación temática - la temática de animales — pero en una formulación tradicional, próxima a la de los epitafios de época clásica, tanto en la estructura de los elementos que incorpora como en la expresión lingüística que les concede (cf. §§ 27-29). Mnasalces, en cambio, une a la innovación temática la incorporación de submotivos concretos - que luego se imponen en imitadores, próximos, como Nicias, o muy posteriores - que en Ánite sólo se hallan en el subgénero menos sometido al canon tradicional - el de epigramas descriptivos y epidícticos - , a saber: el motivo del marco bucólico en general, con submotivos específicos como la invitación al sueño provocada por el cantobatir de las alas, y la descripción de una naturaleza amable y placentera con frescor del agua, sombra y vegetación (cf. $\S 15$ iv). Por tanto, dado que es innegable que exista una relación de imitación (que es evidente no sólo en estos epigramas funerarios, sino también en los descriptivos y epidícticos Ánite 9.144 [15] y Mnasalces 9.333 [15], e incluso en los votivos Ánite 6.123 [1] y Mnasalces 6.128 [5]; cf. Díaz de Cerio, 1996: § 81) es improbable que un imitador adopte una innovación restringiendo su ámbito de aplicación (en favor de mantener el estado previo a la innovación), y en cambio es probable que un imitador amplíe una innovación a otro campo diverso de aquél en el que la encuentra incorporada. 
Bibliografía

AA. VV., L'épigramme grecque, Fondation Hardt pour l'étude de la Antiquité classique 14, Vandoeuvres-Ginebra, 1967.

Adrados, F. R., Historia de la Literatura Griega, López Férez (ed.), Madrid, 1988, 163-4.

Barstone, Greek Lyric Poetry, New York, 1962.

Baale, J. M., Studia in Anytes poetriae vitam et carminum reliquias, Kleynenberg, 1905.

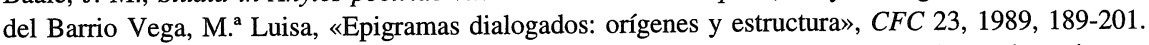

del Barrio Vega, M. ${ }^{a}$ Luisa, «Función y elementos constitutivos de los epigramas funerarios griegos»,

Estudios Clásicos 95, 1989, 7-20.

del Barrio Vega, M. a Luisa, Epigramas funerarios griegos, selección, traducción y comentario, Madrid, 1992.

Brioso, M., Historia de la Literatura Griega, López Férez (ed.), Madrid, 1988, p. 781 y ss.

Cameron, A., The Greek Anthology from Meleager to Planudes, Oxford, 1993.

Campbell, D., The Golden Lyre. The Themes of the Greek Lyric Poets, Londres, 1983.

Couat, A., Alexandrian Poetry under the first three Ptolemies, 324-222 B.C., Londres - Nueva York, 1931.

Díaz de Cerio Díez, M., «Los sub-géneros de epigrama descriptivo y epidíctico en Ánite de Tegea», Homenaje al Prof. Fernando Gascó, Sevilla, 1996.

Fernández-Galiano, M., Antología Palatina. I: Epigramas Helenísticos, Madrid, Gredos, 1978.

Fernández-Galiano, M., Historia de la Literatura Griega, López Férez (ed.), Madrid, 1988, p. 842-5.

Friedländer, P. - Hoffleit, H., Epigrammata. Greek inscriptions in Verse from the Beginning to the Persian Wars, Berkeley, 1948.

Gnoli-Vernant, J. P., La Mort, Les morts dans les sociètes anciennes, París -Cambridge, 1982.

Gow, A. S. F., The Greek Anthology. Sources and Inscriptions, Londres, 1958.

Gow, A. S. F. - Page, D. L., The Greek Anthology: Hellenistic Epigrams I y II, Cambridge, 1965.

Gow, A.S.F. - Page, D. L., The Greek Anthology: The Garland of Philip, I y II, Cambridge, 1968.

Guarducci, M., Epigrafia greca, I, II y III, Roma, 1967, 1969 y 1974.

Herlinger, G., «Totenklage um Tiere in der antiken Dichtung», Tübinger Beiträge, 8, 1930.

Hutchinson, G. O., Hellenistic Poetry, Oxford, 1988.

Kaibel, G., Epigrammata Graeca ex lapidibus collecta, Berlín, 1878.

Körte, A., Hellenistic Poetry, New York, Columbia U. Press, 1929.

Lesky, A.,Historia de la Literatura Griega, Madrid, 1985.

Page, D. L., Epigrammata Graeca, Oxford, 1975.

Page, D. L., Further Greek Epigrams. Epigrams before A. D. 50 from the Greek Anthology and other Sources, Cambridge, 1981.

Paton, W. R., The Greek Anthology I-V, Cambridge, Loeb, Massachusetts-Londres, 1916-1918.

Peek, W., Griechische Vers-Inschriften I, Grabepigramme, Berlín, 1955 (reimpr. Chicago, 1988).

Preger, Th., Inscriptiones Graecae metricae ex scriptoribus praeter Anthologiam collectae, Leipzig, 1891. (Citado por Waltz)

Rasche, W., De Anthologiae graecae epigrammatis, quae colloquii formam habent, Münster, 1910.

Raubitschek, A. E., «Das Denkmal-Epigramm», L' Epigramme Grecque, Foundation Hardt pour l'étude de l' Antiquité classique 14, Ginebra, 1968, pp. 1-36.

Reitzenstein, R., Epigramm und Skolion. Ein Beitrag zur Geschichte der Alexandrinischen Dichtung, Giessen, 1893.

Reitzenstein, R., «Anyte», RE, 1, Stuttgart, 1894, cols. 2654-5.

Rodhe, E., Psyche. Seelenkult und Unterblichskeitsglaube der Griechen (trad. cast. Barcelona, 1973).

Russell, D. A. (ed.), Antonine Literature, Oxford, Clarendon Press, 1990.

Symonds, J. A., Studies of the Greek Poets, London, 1920.

Tarán, S. L., The art of variation in the Hellenistic Epigram, Leiden, 1979.

Trypanis, C. A., Greek Poetry from Homer to Seferis, Londres -Boston, 1981.

Vermeule, E., Aspects of Death in Early Greek Art and Poetry, (trad. de Melena, Méjico, 1974). 
Waltz, P., L'Antologie Grecque, París, VII y VIII, Collection des Universités de France. Société d'Edition «Les Belles Letres», París, 1957. P. Waltz, L'Antologie Grecque, París, tomo IV (libro VII), Collection des Universités de France. Société d’Edition «Les Belles Letres», París, 1960.

Weber, L., «Steinepigramm und Buchepigramm», Hermes 52, 1917, pp. 536-57.

Webster, T. B. L., Hellenistic Poetry and Art, Londres, 1964.

Weisshäupl, R., Die Grabgedichte der Griechischen Anthologie, Viena, 1989.

Wilamowitz, U. von, Die Hellenistiche Dichtung in der Zeit des Kallimachos, I y II, Berlín, 1924. 